DOI: $10.12957 /$ teias.2021.62080

\title{
PAULO FREIRE E MARTIN-BARÓ, CAMINHOS CRUZADOS: Um ensaio de compreensão sobre consciência e educação
}

\author{
Ruth Maria de Paula Gonçalves \\ Valeska Mariano de Castro
}

Resumo

O artigo traz o complexo categorial de Paulo Freire, destacando sua influência nos estudos de Martín-Baró, buscando evidenciar a contribuição de tais fundamentos na objetivação de atividades educativas voltadas ao adolescente na escola pública, considerando a consciência como norte. Nesse sentido, intentamos revisitar obras dos autores referidos, as quais são pertinentes ao cerne de nossa questão central. Com efeito, os lineamentos teóricos freirianos da Pedagogia do Oprimido são examinados no contexto da práxis psicológica pensada por Martin-Baró. Ademais, o artigo intitulado, além de estudos que tratem da questão do adolescente como sujeito social e historicamente mediado são a bússola para analisar as categorias consciência e conscientização no que se refere a práxis. Iluminados pela ontologia marxiana e nos apoiando em Vigotski, Leontiev, Montero, Lane e Góis, buscamos trazer uma perspectiva do desenvolvimento humano, em particular, a adolescência, identificando limites e possibilidades do quefazer da psicologia e da educação; diante da relação de opressão vivida pelo homem no contexto do antagonismo entre capital e trabalho.

Palavras-chave: consciência; psicologia; educação; pedagogia.

\section{PAULO FREIRE AND MARTIN-BARÓ, PATHS CROSSED: An Understanding Essay on Consciousness and Education}

\begin{abstract}
The article brings Paulo Freire categorical complex, highlighting his influence on Martín-Baró studies, seeking to highlight the contribution of such foundations in the objectification of educational activities aimed at adolescents in public schools, considering consciousness as the north. In this sense, we intend to revisit works by the authors, which are pertinent to the core of our central question. Indeed, the theoretical guidelines of Freire's Pedagogy of the Oppressed are examined in the context of the psychological praxis thought of by Martin-Baró. Furthermore, the article entitled, in addition to studies that deal with the issue of the adolescent as a socially and historically mediated subject, are the compass to analyze the categories of conscience and awareness regarding praxis. Illuminated by Marxian ontology and relying on Vygotski, Leontiev, Montero, Lane and Góis, we seek to bring a perspective of human development, particularly adolescence, identifying limits and possibilities for what to do in psychology and education; facing the oppressive relationship experienced by man in the context of the antagonism between capital and labor.
\end{abstract}

Keywords: conscience; psychology; education; pedagogy.

\section{PAULO FREIRE Y MANTIN -BARÓ, CAMINOS CRUZADOS: Una prueba de comprensión de conciencia y educación}

Resumen

El artículo trae el complejo categórico de Paulo Freire, destacando su influencia en los estudios de MartínBaró, buscando resaltar el aporte de tales fundamentos en la objetivación de las actividades educativas dirigidas a los adolescentes en las escuelas públicas, considerando la conciencia como el norte. En este 
sentido, pretendemos volver a visitar los trabajos de los autores mencionados, que son pertinentes al núcleo de nuestra pregunta central. En efecto, los lineamientos teóricos de la Pedagogía del Oprimido de Freire se examinan en el contexto de la praxis psicológica pensada por Martin-Baró. Además, el artículo titulado, además de los estudios que abordan el tema del adolescente como sujeto mediado social e históricamente, son la brújula para analizar las categorías de conciencia y conciencia en relación con la praxis. Iluminados por la ontología marxista y apoyándonos en Vygotski, Leontiev, Montero, Lane y Góis, buscamos traer una perspectiva del desarrollo humano, en particular la adolescencia, identificando límites y posibilidades de qué hacer en psicología y educación; frente a la relación opresiva que vive el hombre en el contexto del antagonismo entre capital y trabajo.

Palabras clave: conciencia; psicología; educación; pedagogía

\section{INTRODUÇÃO}

Estamos atravessando um momento crítico no que se refere a apropriação do conhecimento universal, decorrente da fragmentação da relação entre teoria e prática, o que repercute negativamente no processo de formação humana integral. Tal ruptura, engendrada pelo antagonismo entre capital e trabalho incide diretamente na formação das funções psíquicas superiores dificultando a apreensão do real e o desenvolvimento pleno das potencialidades humano - genéricas (TOMMIO, FACCI, 2009). A exploração do homem pelo homem decorrente do trabalho alienado aprisiona consciências atingindo frontalmente o que há de mais singular no tornar-se humano, desvirtuando o reflexo consciente da realidade objetiva na subjetividade. Trazer para o debate as teorias de Paulo Freire e Martín-Baró com vistas a discutir os impedimentos e as possibilidades de seus lineamentos teóricos na perspectiva da emancipação humana, em particular, na formação de adolescentes da escola pública, é tarefa nossa, nos contornos deste artigo. Para atingir tal objetivo, nos debruçamos sobre os conceitos de consciência; educação e adolescência dentro do referencial teórico de base para este artigo.

O escrito, ora em foco, é decorrente de uma pesquisa que constou de duas dimensões teórico-metodológicas, a saber: bibliográfica e documental. Na dimensão bibliográfica buscamos fazer um levantamento de duas, das principais obras de Paulo Freire: Pedagogia do Oprimido e Pedagogia da Autonomia e de um artigo de Martín - Baró, no qual a categoria consciência, bem como o cerne do pensamento de Freire; toma lugar de destaque. As categorias centrais de nosso estudo: consciência e educação estavam articuladas, com o objetivo de evidenciarmos aproximações dos lineamentos teóricos dos dois autores, além de dialogarem com a questão do adolescente como sujeito social e historicamente mediado (Vigotski, Leontiev, Bock). Este foi o aporte necessário para analisarmos as categorias consciência e conscientização no que se refere a práxis. Ancorados na ontologia marxiana, base da teoria Vigostkiana. consideramos o trabalho como anto-gênese do ser social.

Nesse sentido, na pesquisa realizada, apoiamo-nos em Vigotski, Leontiev, Montero, Lane e Góis, buscando identificar limites e possibilidades do quefazer da psicologia e da educação diante da exploração do homem pelo homem edificada pelo antagonismo entre capital e trabalho. Para efeito deste escrito, destacamos apenas dados oriundos dimensão bibliográfica. 
DOI: $10.12957 /$ teias.2021.62080

\section{PAULO FREIRE E OS TRÊS NÍVEIS DISTINTOS DE DESENVOLVIMENTO DA CONSCIÊNCIA: MÁGICA, INGÊNUA E CRÍTICA.}

Ao criar sua teoria da consciência mágica, FREIRE (1977), indica que o homem dominado pela consciência mágica está imerso, circunscrito a áreas estreitas de interesse e preocupações, não podendo, portanto, apreender os problemas além de sua esfera biológico-vital.

O homem dominado nesse tipo de consciência é como se fosse cego e limitado, incapaz de perceber sua situação. Segundo o autor, o homem e, pois, só um ser vegetativo, não se existencializa porque não percebe a realidade como um mundo de desafios. Conseguinte, o sistema educacional é precário e seletivo, apresentando altas taxas de analfabetismo. Assim, esta sociedade passou a ser dependente, resultando em consciência dominada e toda consciência dominada não pode afastarse suficientemente da realidade, a fim de objetivá-la e conhecê-la na forma crítica.

Se não questiona e não dialoga, deixa de compreender. Não compreendendo, sente-se impedido de julgar, valorar, decidir e agir. É conduzido pela história, mas não se faz sujeito protagonista dela, à medida que se resigna e não atua para transformar suas estruturas elementares. Por isso o humano que apresenta a consciência mágica se vale de rituais e cerimônias de cunho religioso, fonte da precária explicação que alimenta para os fatos que o afetam.

Quase sempre este fatalismo está referido ao poder do destino ou da sina... ou a uma distorcida visão de Deus. Dentro do mundo mágico ou místico em que se encontra a consciência oprimida, quase sempre imersa na natureza, encontra no sofrimento, produto da exploração em que está, a vontade de Deus, como se ele fosse o fazedor desta desordem organizada (Freire, 1978, p. 52-53).

Freire (1981) afirma que, na medida em que o oprimido amplia seu poder de captação e de resposta aos problemas de seu meio, aumenta o seu poder de dialogação. Seus interesses e preocupações agora, se alongam as esferas mais amplas do que a simples esfera vital. Assim, as contradições e os conflitos vêm a superfície, onde a consciência ingênua ganha destaque. Ela busca um compromisso, repleto do fanático e de uma entrega irracional. Assim, esta consciência é vista por ações mágicas porque a compreensão também é mágica, onde há uma preferência pelo tempo passado, achando que este é melhor que o tempo presente.

Já a consciência crítica, segundo Freire (1981) é fruto de uma educação dialogada e ativa. Está voltada para a responsabilidade social e política, caracterizando-se pela profundidade na interpretação dos problemas e pela substituição das mágicas por princípios causais. Por procurar testar os achados e se dispor sempre a visões da prática do diálogo e não pela polêmica. Na medida em que o homem ultrapassa a esfera da tomada de consciência ingênua para a crítica constrói a maneira de fazer a leitura da realidade, tornando-a mais completa. Desse modo torna-se homem inserido e integrado ao mundo superando a simples apreensão dos fatos, consolidando o ponto fundamental para a conscientização.

A evolução do nível mais rudimentar para o mais complexo, portanto, seria a evidência do acontecimento do aprendizado (ROMAÑA, 2004). Martín-Baró, compreende que a mesma não pode ser compreendida desconectada da realidade histórico-social do sujeito e da classe ao qual ele pertence e que é dever da práxis psicológica emancipadora ajudar o sujeito a tomar consciência dessa realidade a fim de se libertar dos mecanismos de opressão e de alienação que embargam seu desenvolvimento pleno (DIAS, 2020). Ambos possuem uma ponte entre si e, enquanto Freire sugere a Educação como caminho possível para a emancipação, Martin-Baró aponta a Psicologia 
da Libertação 1 enquanto uma alternativa. Ambos situam a libertação como horizonte da formação humana integral, considerando a opressão sofrida pelos povos dominados na América Latina. Educação e psicologia caminham lado a lado nos estudos do educador brasileiro e do psicólogo salvadorenho.

Isto posto, a perspectiva Histórico-Cultural de Vigotski entende que na adolescência as funções psicológicas superiores aparecem, não como continuação, mas como alfo qualitativamente novo. Vale ressaltar que estas transformações se vinculam ao aparato biológico do adolescente em formação, mas não é este o elemento predominante, uma vez que são produtos do desenvolvimento histórico da humanidade. Com efeito, a percepção, a atenção, a memória, imaginação articulam-se com a formação de conceitos, sendo a palavra um suporte necessário. Sentido pessoal e significado social performam a subjetividade, e desse modo a educação escolar se faz de extrema relevância na relação entre pensamento e linguagem. Tal teoria compreende o desenvolvimento do sujeito humano para além do modelo geneticista vigente em nossa sociedade, compreendendo o aprendizado e a realidade sócio-histórica para esse processo (BOCK, 2004).

Somando-se ao exposto, traremos uma compreensão da Educação a partir das Obras de Paulo Freire; principalmente Pedagogia do Oprimido (FREIRE, 2019a) e Pedagogia da Autonomia (2019b) Breves notas de estudos da psicodramatista argentina Maria Alicia Romaña, idealizadora do psicodrama pedagógico ${ }^{2}$ (ROMAÑA,1987, 2004) permeiam nossas elaborações.

A problemática de uma educação bancária ${ }^{3}$, assim sendo, colabora para a manutenção de um sistema alienador e opressor da classe trabalhadora. Fato este que serve aos propósitos das ideologias dominantes e prejudica a démarche sócio-histórica das coletividades humanas. Outrossim, reiteramos a importância de uma educação perspectivada na emancipação dos sujeitos e uma atitude profissional por parte da Psicologia que corrobore com o mesmo fim. Esperamos, com os lineamentos postos neste artigo, convidá-los a "co-construirem" uma intervenção na educação da juventude das escolas públicas brasileiras que dialogue com os autores em tela.

\section{SOBRE EDUCAÇÃO E CONSCIÊNCIA}

A pedagogia de Paulo Freire, em especial, os escritos sobre a Pedagogia do Oprimido constituem um marco teórico nos estudos de educação de jovens e adultos no Brasil. Reconhecido por sua magnitude no que se refere à alfabetização, Freire tem seu nome cravado na educação de diversos países. No tocante aos estudos sobre Psicologia Social Comunitária na América Latina, temos como exemplo, o entrecruzamento do pensamento de Martín-Baró e Montero, permeados pela Pedagogia freiriana. Vale ressaltar que Góis (2005) ao traçar um quadro teórico que orienta a Psicologia Comunitária, põe em destaque os nomes do salvadorenho Martín-Baró, da brasileira Silvia Lane (1994) e de Maritza Montero (1982), venezuelana, reconhecendo que a práxis neste campo, é tributária de suas teorias.

\footnotetext{
1 Surgiu na América Latina durante a década de 1980. Trata-se de uma psicologia crítica que busca promover a libertação das populações oprimidas através do processo de conscientização e da participação ativa dos sujeitos (BURTON, 2013).

2 "A Pedagogia do Drama é decorrente de uma visão educacional que se propões a colaborar no desenvolvimento de uma consciência crítica e reflexiva para obter uma compreensão do mundo e suas contingências com autonomia e compromisso." (ROMAÑA, 2004, p.46). Para atingir tal objetivo, utiliza técnicas e metodologia psicodramáticas, além de uma contribuição Freiriana e Vygotskiana acerca da compreensão da Educação.

3 Modelo de ensino no qual o discente é apenas um "depósito" de um conhecimento que lhe é simplesmente transferido pelo professor; é desconectado da realidade do aluno e sem sua participação ativa. Não há desenvolvimento dos diferentes estágios de consciência ou compromisso com práticas libertadoras e transformadoras (FREIREb, 2019).
} 
Preocupados com a formação humana integral, por conseguinte com a devida relação entre teoria e prática, objetividade e subjetividade na práxis psicológica, nos propomos a examinar o quefazer psicológico nos estudos de Martín-Baró evidenciando as aproximações da obra deste autor com os lineamentos teóricos de Paulo Freire, buscando evidenciar em que medida tais estudos podem fortalecer a realização de atividades educativas emancipatórias na formação crítica do adolescente oriundo da classe trabalhadora. Nesse sentido recorremos ao complexo categorial presente no livro Pedagogia do Oprimido, por considerarmos uma obra de significativa relevância social, por sua contribuição ao debate sobre a exploração do homem pelo homem, na qual observamos as raízes da obra freiriana, a qual iluminou inúmeros trabalhos nas áreas das ciências humano-sociais no que se refere a conscientização e libertação.

Para Freire (1987), a luta pela humanização é possível, uma vez que a desumanização é um fato concreto da história, ou seja, não é um destino dado, mas resultado da injustiça engendrada pelos opressores contra os oprimidos. Com base nessa compreensão, Freire (1987, p. 30) reconhece que [...] a luta pela humanização, pelo trabalho livre, pela desalienação, pela afirmação dos homens como pessoa, como seres para si torna-se plena de sentido.

Por sua vez Leontiev (1978) considera que o homem não nasce homem, mas se torna homem a partir da riqueza material e intelectual produzida pela humanidade. Ou seja, não se trata de uma passagem dominada pela genética, da qual depende a espécie, mas, especialmente da leis sócio-históricas que regem a consolidação do gênero humano.

A exploração do homem pelo homem nos países da América Latina enceta os lineamentos teórico-práticos dos estudos de Freire e Martín-Baró, sendo este um dos laços que os aproxima. Com efeito, Góis (2005), ao trazer dados históricos sobre a Psicologia Social, reconhece que seu surgimento se dá a partir da problematização social oriunda de concepções divergentes em relação a questão social. Por um lado, uma corrente oriunda de modelos clássicos desta área, ahistoricização, descontextualização, universalização, descompromisso com os problemas da classe explorada. Contrapondo-se a esta corrente, surgia uma concepção crítica de Psicologia Social cujos contornos históricos buscavam dar conta das relações sociais de dominação nas sociedades latinoamericanas nas quais as diferenças culturais eram gritantes. Góis (2005) reconhece como representantes desta corrente, Martín-Baró, Silvia Lane e Maritza Montero, cujas obras voltavamse para a formulação de uma Psicologia Social Crítica, preocupadas com a transformação do real a partir do homem em seu movimento histórico. Conscientização e participação social eram categorias-chave nesse processo. Martín-Baró (1996) parte do questionamento feito por dois psicólogos franceses em 1968, quando ao observarem o crescente número de psicólogos sendo formados na França, se perguntaram: para que psicólogos? A inquietude se dava pelo fato de que os teóricos atribuíam o papel da psicologia na transformação das pessoas, sem, no entanto, buscar a transformação da sociabilidade. Também deixavam entrever que esta transformação a nível individual não engendraria uma mudança significativa.

Partindo desse prisma, o psicólogo salvadorenho se opunha ao subjetivismo e ao psicologismo reconhecendo que não se tratava de conceber um que fazer psicológico partindo de cada um sobre seus próprios questionamentos ou por suas opções políticas, mas antes e fundamentalmente, como assinalara Martín-Baró (1996) examinar para onde vai, levado por seu próprio peso, o quefazer psicológico; que efeito objetivo a atividade psicológica produz em uma determinada sociedade (Martín-Baró, s. d.). Tal limitação não era exclusiva da Psicologia, mas das ciências humano-sociais que se consolidaram orientadas para servir ao capital, minadas pela ascensão da burguesia, classe dominante no final do século XVIII para o início do século XIX. É no contexto de fragmentação cabeça-mão, decorrente do modo de produção capitalista que a Psicologia já reconhecida como Ciência segue, elegendo como objeto de estudo o comportamento 
humano. Nesse sentido, o psicólogo salvadorenho chama a atenção para a processualidade que permeia as bases históricas da atividade e do pensamento humano, no que se refere a práxis do psicólogo, reconhecendo que por sermos social e historicamente mediados, é imperativo o que já foi feito, o que poderíamos ter feito, o que poderemos fazer na psicologia como ciência e profissão no que tange a função social.

Partindo desse pressuposto, elege o estudo da consciência como contraponto aos limites impostos pelas teorias que advogam a conduta ou o comportamento estritamente observável como objeto da psicologia. Entendendo a consciência como uma realidade psicossocial, o psicólogo salvadorenho considera a relação entre a imagem que o indivíduo tem de si mesmo, que não se produz de forma solitária, constituindo a processualidade histórica enredada em meio ás representações sociais. Retomando estudos de Gibson e Baron, Martín-Baró (1996, p.14) assinala que: A consciência não é simplesmente o âmbito privado do saber e sentir subjetivo dos indivíduos, mas, sobretudo, aquele âmbito onde cada pessoa encontra o impacto refletido de seu ser e de seu fazer na sociedade, onde assume e elabora um saber sobre si mesmo e sobre a realidade que lhe permite ser alguém, ter uma identidade pessoal e social. A consciência é o saber, ou o não saber sobre si mesmo, sobre o próprio mundo e sobre os demais, um saber práxico mais que mental, já que se inscreve na adequação às realidades objetivas de todo comportamento, e só condicionada parcialmente se torna saber reflexivo (Gibson, 1966; Baron, 1980).

Ainda sobre a relação entre individual e social na formação da consciência, o psicólogo salvadorenho destaca que o conhecimento fundamental para o que fazer psicológico não reside no saber explícito, mas aquele que se inscreve nas entrelinhas do senso comum, não formalizado, ideologicamente naturalizado. Daí, não descartar a categoria comportamento humano, desde que se resguarde tanto seu significado pessoal e social, assim como o sentido historicamente perspectivado e a partir daí manifesto. Nesse sentido, ao discutir esse quefazer Martín-Baró (1996, p 15.) destaca a categoria trabalho ao afirmar que: Trabalhar não é apenas aplicar uma série de conhecimentos e habilidades para satisfação das próprias necessidades; trabalhar é, antes e fundamentalmente, fazer-se a si mesmo, transformando a realidade, encontrando-se ou alienandose nesse quefazer sobre a rede das relações interpessoais e intergrupais.

Com efeito, as aproximações dos lineamentos teóricos de Paulo Freire ao quefazer psicológico nos estudos de Martin-Baró, evidenciam caminhos possíveis na efetivação de atividades educativas emancipatórias com adolescentes de escolas públicas. Desse modo, ressaltamos a relevância da psicologia da libertação e dos lineamentos teóricos presentes na pedagogia do oprimido e na pedagogia da autonomia enquanto práxis libertadoras dos sujeitos em processos educativos. A psicologia analisar a possibilidade da pedagogia do drama como aliado nos processos emancipatórios no contexto educacional.

\section{EDUCAÇÃO E FORMAÇÃO DO SUJEITO COMO SER SOCIAL E HISTORICAMENTE MEDIADO}

Pensando em uma compreensão histórico-cultural do sujeito, é imprescindível o discutir sobre a relação que este estabelece em sua démarche do desenvolvimento e a educação. Os seres humanos; sendo históricos, relacionais e sociais; são afetados tanto por sua realidade filogenética quanto ontológica, e encontram em sua cultura e nos outros bases importantes para desenvolverse e tornar-se sujeito.

Vygotski, em sua compreensão sociointeracionista a respeito do desenvolvimento humano, já afirmava a importância da educação para o desenvolvimento, principalmente ao trazer conceitos 
como a zona de desenvolvimento proximal ${ }^{4}$ (RABELO, PASSOS; DAVIS, OLIVEIRA, 2010; TOMIO, FACCI, 2009). Em seus estudos há um notável destaque da importância das relações estabelecidas em situação de aprendizagem para o ser humano em sua jornada pela apreensão de sua realidade sócio-histórica.

Os processos pelos quais a cultura é apropriada pela consciência humana é de central importância nas discussões a respeito de temas como educação e emancipação dos sujeitos (FREIRE, 2019b). As escolas são um dos principais cenários para tais movimentos a esse processo de "sujeitamento" humano; no qual valores, normas sociais, desenvolvimento de funções psicológicas superiores (inteligência, memória etc.) são trabalhados. (ROMAÑA, 2004; SOUZA, DRUMMOND, 2018; DAVIS, OLIVEIRA, 2010). Por isso, e pensando que os educandos aprendem tanto um método quanto um conteúdo, é preciso refletir sobre a maneira como o trabalho pedagógico vem sendo conduzido no Brasil atualmente e, devido ao enfoque da presente pesquisa, em especial, nas escolas públicas, ambiente por excelência para que as consciências possam evoluir de forma crítica acerca do real em movimento.

Segundo Brandão (1981, p.22), Paulo Freire contra toda esta proposta de educação para reprodução de conteúdo, cria um método que parte do diálogo entre educando e educador, em que ambos contribuem para o aprendizado, que valoriza a relação entre quem educa e quem é educado, onde a educação (...) será um ato coletivo solidário, um ato de amor, dá para pensar sem susto, não pode ser imposta. Nesta relação, ambos, quem ensina e quem aprende, são considerados educadores e educando simultaneamente, porque juntos, lado a lado se ensina, lado a lado se aprende.

A construção do método se dá por pessoas da comunidade, onde em grupos, chamados de círculo de cultura que envolve a ação educadores e educandos, "[...] a partir daí que se passa a construção do trabalho, buscando reunir um número significativo de símbolos mecânicos". (BRANDÃO, 1981, p. 22).

Victor Henrique Paro (2010) ao estudar o papel do diretor e da administração escolar no ensino brasileiro, denuncia uma finalidade educativa orientada para servir aos interesses de uma lógica do mercado neoliberal. Uma prática pedagógica que, ainda segundo o autor, muitas vezes importa modelos administrativos e metodológicos de outros nichos do mecanismo capitalista e os aplica à educação, gerando inúmeras contradições no ambiente escolar.

Contradições estas, claro, que vêm da especificidade do trabalho educativo. Quando se tem em vista a educação enquanto processos de construção de contextos favoráveis a elaboração de pensamentos críticos, reflexivos e de sujeitos autônomos em seu próprio aprender (FREIRE, 2019b; ROMAÑA, 2004; SOUZA, DRUMMOND, 2018), torna-se evidente a incompatibilidade entre esta e a simples manutenção de um sistema pedagógico que objetiva produzir homens enquanto coisas, simples mão de obra para o mercado.

A educação, inicialmente, deve objetivar a transformação de consciência e o tornar-se sujeito nas relações educacionais, principalmente, na relação professor-aluno (PARO, 2010). Essa finalidade está em concordância com o que Paulo Freire (2019a, 2019b) compreende como processo educativo. É evidente que, ainda segundo o autor, esse processo de transformação de consciência e de reflexão deve ultrapassar o mero discurso da superioridade intelectual academicista e precisa estar atrelada à uma práxis comprometida de fato com a libertação dos sujeitos e construída com os grupos oprimidos (FREIRE 2019b).

\footnotetext{
${ }^{4}$ Conceito apresentado por Vygotski que discorre sobre a distância entre um nível de desenvolvimento real (capacidade para resolver problemas de maneira independente) e o desenvolvimento proximal (capacidade para solucionar problemas com a ajuda de alguém mais experiente) (DIAS, OLIVEIRA, 2010)
} 


\section{O ADOLESCENTE SOB A ÓTICA HISTÓRICO-CULTURAL}

Como apontam Tomio e Facci (2009) e Bock (2004), a compreensão acerca da adolescência ao logo da história do estudo do desenvolvimento humano é atravessada por uma lógica biologicista. Os teóricos que se aventuraram a compreender esse fenômeno, quando o fizeram, atribuíam a esse período características muitas vezes negativas; imaginando-o como apenas um período de transição entre infância e vida adulta; e dissociados de suas realidades sócio-históricas.

Vygotsky e Leontiev, no entanto, ao pensarem em desenvolvimento, trazem uma perspectiva diferente. Para Leontiev (1978) o homem não nasce homem, mas se constitui enquanto tal a partir das riquezas materiais e intelectuais disponíveis em seu meio. Vygostsky, quanto a concepção sócio-interacionista de sujeito, compreende que as relações que este estabelece são fundamentais para o seu processo de tornar-se humano (TOMIO, FACCI, 2009). Por essas visões, ambos consideram o desenvolvimento enquanto processo ativo, social e relacional, ultrapassando a noção de que se trata de uma mera divisão de etapas quanto à maturação biológica dos corpos.

Tendo isso em mente, faz-se necessário pensar sobre as questões que atravessam a adolescência brasileira. Ao nos determos pela presença hegemônica do modelo econômico neoliberal e a forma com a ideologia dominante se perpetua no imaginário dos grupos oprimidos por meio de mecanismos de controle; como o ambiente jurídico e educacional; encontramos uma adolescência permeada de demandas associadas ao quefazer profissional inserido em uma lógica produtivista e desigual na sociedade capitalista (PARO, 2010). Muito cedo ao adolescente é cobrado um ser no mundo atrelado ao mercado de trabalho; no entanto revela-se um recorte de classe ao se pensar na situação de desigualdade social. Somada a essa situação, deparam-se com as questões afetivas, psicológicas e sociais relacionadas ao não pertencer a um grupo bem delimitado, devido a uma sociedade que ainda pouco se detém sobre a compreensão da adolescência e a não definição do seu lugar social para além da escola (TOMMI, FACCI, 2009).

Retomando a discussão apresentada ao nos determos sobre a forte relação ente educação e sujeito e da sua participação em seu vir a ser, podemos pensar nas graves consequências que uma educação descompromissada com sua própria finalidade pode ocasionar. Devido as especificidades socioeconômicas e culturais, a juventude brasileira que frequenta o sistema público de ensino se depara com a problemática da evasão escolar. Esse fenômeno já é presente por muito tempo na história da educação brasileira e tem causas multifatoriais que tanto são geradas pelo funcionamento interno das escolas (despreparo docente, desmotivação para o ensino, condições precárias de trabalho, gestão autoritária e descompromissada etc.) quanto por dinâmicas "externas" (estrutura familiar; desigualdade social, políticas públicas de ensino, violência, saúde pública etc.) (FERREIRA, OLIVEIRA, 2020).

A evasão escolar acarreta em problemas não só a sociedade como um todo, que enfrenta fatores como marginalização dos sujeitos não escolarizados inseridos em uma sociedade excludente baseada na qualificação da mão de obra (FERREIRA, OLIVEIRA, 2020), também implica em perdas para os processos desenvolvimentais dos adolescentes, já que estes terão acesso à cultura e às demais riquezas intelectuais e materiais da humanidade dificultado devido a concentração de recursos disponíveis nas mãos de uma classe dominante letrada e qualificada. Essa privação, além da mediação precária realizada em outros momentos do desenvolvimento associado a questões sociais como violência, privação de direitos, gravidez na adolescência e inserção precoce no mercado de trabalho, irão gerar obstáculos para um desenvolvimento pleno do sujeito, já que as relações que este estabelece com seu meio e os outros estará prejudicada (FERREIRA, OLIVEIRA, 2020; LUCÁCKS, 1978; BOCK, 2004). 
Psicologia da libertação, pedagogia da libertação e a pedagogia do drama enquanto práxis interventivas para a juventude nas escolas brasileiras

A pedagogia da Libertação para Paulo Freire, enaltece a visão de homem e que somente ele e capaz de agir conscientemente na realidade, identificada por ele como práxis humana, a unidade indissolúvel entre a ação e a reflexão sobre o mundo. Segundo Freire (1980), num primeiro momento a realidade não se dá aos homens como objeto cognoscível por sua consciência crítica. Esta tomada de consciência não é ainda a conscientização porque esta consiste no desenvolvimento crítico da tomada de consciência.

A conscientização implica que seja ultrapassada a esfera espontânea da apreensão da realidade para chegar a uma esfera crítica na qual a realidade se dá como objeto cognoscível e no qual o homem assume uma posição epistemológica. A conscientização e um teste da realidade. Quanto maior a conscientização mais se penetra na interpretação das relações dos fenômenos do objeto. A conscientização não pode ser vista como uma posição falsamente intelectual.

A conscientização não se dá sem o ato de ação-reflexão, ou seja, sem a práxis. É nesta perspectiva dialética que se caracteriza a transformação do mundo, onde há consciência histórica e os homens assumem o papel de sujeitos que transformam o mundo.

Tomando esta relação como objeto de sua reflexão crítica, os homens esclarecerão as dimensões obscuras, que resultam de sua aproximação com o mundo. A criação da nova realidade, tal como está indicada na crítica precedente, não pode esgotar o processo de conscientização. A nova realidade deve tornarse como objeto de sua nova reflexão crítica. Considerar a nova realidade como algo que não possa ser tocado, representa uma atitude tão ingênua e reacionária, como afirmar que a antiga realidade é intocável. (FREIRE, 1980, p. 27)

Ao refletir sobre o cenário descrito até aqui, torna-se necessário pensar em uma práxis psicológica compromissada com a emancipação da juventude brasileira, visando a catalisar processos de transformação de consciência e rompimento com padrões de comportamento alienados que servem aos interesses das classes dominantes. Para tal, os autores do artigo consideram a psicologia da libertação (MARTÍN-BARÓ, 1996; BURTON, 2013), a Pedagogia da Libertação e a Pedagogia do Drama (ROMAÑA, 2004, SOUZA, DRUMMOND, 2018) como caminhos possíveis para atingir esse fim.

A psicologia da libertação pensada por Martin-Baró (1996) define o quefazer da psicologia como uma ciência que deve ser compromissada com a conscientização dos sujeitos, que implica em um "[...] processo dinâmico, conflituoso, de transformação do ser humano que, de forma pessoal e social, pensa e atua numa realidade histórica num vir a ser (devir) que se efetiva na práxis, envolvendo suas dimensões psicológicas, sociais e políticas". (MENDONÇA, 2017, p. 123).

A Pedagogia da Libertação, aqui destacadas através das obras Pedagogia do Oprimido e Pedagogia da Autonomia, trazem o contraponto a relação opressão entre opressor e oprimido presente na sociabilidade do capital, a qual reverbera na escola, na educação de adolescentes da escola pública. Sendo esta fase de desenvolvimento, própria da evolução da consciência, através da ampliação do pensamento sobre as condições objetivas de ser e estar no mundo como sujeito mediado, materializado pela linguagem; a educação para a libertação das consciências, é práxis necessária.

Já a Pedagogia do Drama, organizada pela pedagoga e psicodramatista argentina Maria Alicia Romaña, bebe de influências da compreensão de Paulo Freire e Vygotsky acerca de 
consciência e educação bem como da visão de Moreno de sujeito em sua teoria socionômica ${ }^{5}$, se valendo de técnicas e recursos do psicodrama e do sociodrama para promover situações de aprendizado em diferentes esferas (ROMAÑA, 2004). Ao falar sobre a potência dessa metodologia, destaca o uso do sociodrama para investigação e manejo das questões grupais; da compreensão da dinâmica dos papéis sociais dos sujeitos (role-playing); jogos dramáticos e outros recursos socionômicos para atrelar realidade vivida pelos sujeitos com o conhecimento adquirido. Essa prática, por se valer da ação, invoca a participação direta dos atores educacionais no seu processo, favorece a participação grupal e possibilita reflexões a respeito de valores, cultura e papéis desempenhados e objetiva a promoção do conhecimento crítico e reflexivo que extrapola a lógica do mercado (ROMAÑA, 2004).

Outrossim, esses caminhos teórico-metodológicos provam-se potentes ao pensarmos na construção de espaços escolares propícios ao desenvolvimento pleno da juventude brasileira no setor público. A pedagogia do Drama; compromissada com a práxis promotora de conscientização, corroborando com o pensamento de Martín-Baró, pode promover a ressignificação de papéis sociais ${ }^{6}$ como os de professor, aluno e, até mesmo, adolescente, construindo junto aos próprios jovens, um sentido para o "não lugar" da adolescência no Brasil. Ademais, ao se pensar no uso do sociodrama como desenvolver relacionamentos nas apenas com outras pessoas, mas com conhecimentos, valores e cultura numa perspectiva atualizadora e transformadora (SOUZA; DRUMMOND, 2018), podendo ser possível criar espaços institucionais onde administração, comunidade, corpos discente e docente podem trabalhar relações, promover reflexões e construírem uma gestão mais democrática de ensino (PARO, 2010)). Além de se investigar as demandas dessa juventude, localizando suas necessidades e procurando formas de evitar sua evasão das escolas.

\section{CONSIDERAÇÕES FINAIS}

Diante do presente estudo, consideramos de suma importância pensar numa educação comprometida com uma práxis libertadora para o desenvolvimento pleno da juventude brasileira. Educação esta, promotora de transformações de consciência, colaborando para a transformação do meio, transformando a si mesmo (FREIRE, 2019b; ROMAÑA, 2004).

A partir da pesquisa realizada, reforçamos o uso da Pedagogia do Drama e o sociodrama como caminhos teórico-metodológicos para a fomentação de um contexto possível a pedagogia da autonomia (FREIRE, 2019a). Outrossim, as mesmas também condizem com os pressupostos da psicologia da libertação acerca da práxis da psicologia comprometida com a emancipação dos sujeitos.

Por fim, é necessário pensar que há muito o que se caminhar quando pensamos na educação brasileira. A herança colonial jesuítica, as influências da herança monárquica e, também, da atual lógica liberal impõem vários entraves à atuação dos profissionais da educação que procurem romper com seus paradigmas (PARO, 2010; FERREIRA, OLIVEIRA, 2020). No entanto, os autores ressaltam que, como afirma Paulo Freire (2019b), não devemos nos render ao sentimento

\footnotetext{
${ }^{5}$ A Socionomia, teoria concebida pelo psiquiatra e dramaturgo austríaco J.L.Moreno, compreende o sujeito em relação, valorizando o aspecto das relações interpessoais, bem como o vínculo e o conjunto de papéis - em suas diversas categorias - que desempenham no seu processo de existir (Gonçalves, Wolff, Almeida,1988; Nery, 2018).
}

${ }^{6}$ papéis sociais são "todos os que nos conectam com outras pessoas e coisas através de desempenhos que se produzem na família, na atividade profissional, nos estudos e em todas as relações de nosso cotidiano” (ROMAÑA, 2004, p.32) 
fatalista que a consciência ingênua impõe ao oprimido ao observar a aparente invulnerabilidade dos opressores. A educação, mesmo que a custo de lutas constantes, pode ser um caminho importante para a compreensão e transformação da realidade posta.

Tomando por caminho o percurso que o educando e o educador devem fazer no sentido do reconhecimento da consciência mágica, da necessidade de superação da consciência ingênua, do desvencilhamento dos riscos da consciência fanatizada, então a práxis docente pode contribuir para a construção da criticidade. Portadores da consciência crítica, então os sujeitos da educação estarão melhor preparados para empreenderem a luta pela libertação.

Por fim, a proposta de Freire sempre foi fincada numa educação de conscientização, que deve auxiliar este homem oprimido a ter uma visão profunda da realidade concreta, sendo através da ação do sujeito e da tomada de consciência de seu mundo, que podemos reacender luzes para uma educação que tenha como horizonte a libertação.

\section{REFERÊNCIAS}

BARÓ-MARTÍN, Ignácio. O papel do Psicólogo. Estudos de Psicologia 1996, 2(1), 7-27

BRANDÃO, Carlos Rodrigues. O que é método Paulo Freire, São Paulo: Brasiliense, 1981.

BOCK, Ana. A Perspectiva Sócio-histórica de Leontiev e a Crítica a Naturalização da Formação do Ser Humano: a adolescência em questão. In: Caderno Cedes, Campinas, v. 24, n. 62, p. 26-43, abril 2004. Disponível em <www.cedes.unicamp.br>. Acesso em 12 de jun. de 2014.

BURTON, Mark. Psicologia da libertação: uma práxis crítica construtiva. Estudos de Psicologia. Campinas, n. 30, v. 2, p. 249-259, abr./jun., 2013. Acesso em 12 jan. 2021.

ENGELS, Friedrich. MARX. Karl. A Ideologia Alemã. São Paulo. Boitempo Editorial 2007.

FREIRE, Paulo. A Pedagogia do Oprimido. Rio de Janeiro. Paz e Terra.1987.

FREIRE, Paulo. Pedagogia da autonomia: saberes necessários à prática educativa. Rio de Janeiro/São Paulo: Editora Vozes, 61. ed., 2019a.

FREIRE, Paulo. Pedagogia do Oprimido. Rio de Janeiro/São Paulo: Paz e Terra, 1978, 69.ed., 2019b

FREIRE, Paulo. Educação como prática da liberdade. Rio de Janeiro: Paz e Terra, 17.ed., 1983.

FREIRE, Paulo. Ação cultural para a liberdade. Rio de Janeiro: Paz e Terra, 2. ed., 1977.

GÓIS, Cezar Wagner. Psicologia Comunitária: Atividade e Consciência. Fortaleza: Instituto Paulo Freire. 2005.

LANE, Silvia e CODO, Wanderley (orgs.) Psicologia Social. O Homem em Movimento. São Paulo: Editora brasiliense, 1994.

LEONTIEV, Alexis. O Desenvolvimento do Psiquismo. Lisboa: Livros Horizonte.1978.

MONTERO, Maritza. Teoría y Practica de la Psicología Comunitaria: la tenslón entre comunidad y sociedad. Buenos Aires Argentina. Editorial Paidós. 2003.

MENDONÇA, Gabriel Silveira. O conceito de ideologia em Martin Baró: reflexões a partir do materialismo histórico-dialético. 2017. 190 f. Dissertação (Mestrado) - Curso de Psicologia, Pontíficia Universidade Católica. Campinas, 2017

PARO, Vitor Henrique. A educação a política e a administração: reflexões sobre a prática do diretor escolar. Educação e pesquisa, São Paulo, v.36, n.03, p. 763-768, set./dez., 2010. 
DOI: $10.12957 /$ teias.2021.62080

RABELLO, Elaine; PASSOS, José. Vygotsky e o desenvolvimento bumano. Disponível em https://josesilveira.com/wp-content/uploads/2018/07/Artigo-Vygotsky-e-o-desenvolvimentohumano.pdf. Acesso em 30 ago. 2021.

ROMAÑA, Maria Alicia. Pedagogia do Drama: 8 perguntas e 3 relatos. São Paulo: Casa do psicólogo, 2004.

SENA e SILVA, Fatima. e Aquino, Cassio Braz(orgs.). Psicologia Social:desdobramentos e aplicações. São Paulo: Escrituras, 2004.

SAVIANI, Dermeval. Histórias das Ideias Pedagógicas no Brasil. Campinas: Autores Associados. 2010 SOUZA, Andréa Cláudia de; DRUMMOND, Joceli. Sociodrama na educaşão. Rio de Janeiro: Wak Editora, 2018.

TOMIO, Noeli; FACCI, Maria. Adolescência: uma análise a partir da psicologia sócio-histórica. Rev. Teoria e Prática da Educação, v.12, n.1, p. 89-99, jan./abr. 2009.

VIGOTSKI. Lev. Obras Escolbidas. Tomo. IV.1984.Madris. A Machado Libros SA.

Submetido em agosto de 2021

Aprovado em outubro de 2021

\section{Informações das autoras}

Ruth Maria de Paula Gonçalves

Universidade Estadual do Ceará

E-mail:depaularuth@gmail.com

ORCID: https://orcid.org/0000-0003-0070-4123

Link Lattes: http://lattes.cnpq.br/7515124468091526

Valeska Mariano de Castro

Universidade Estadual do Ceará

E-mail:profvaleskamariano@gmail.com

ORCID: http://orcid.org/0000-0002-0089-6973

Link Lattes: http://lattes.cnpq.br/3865304348046769 